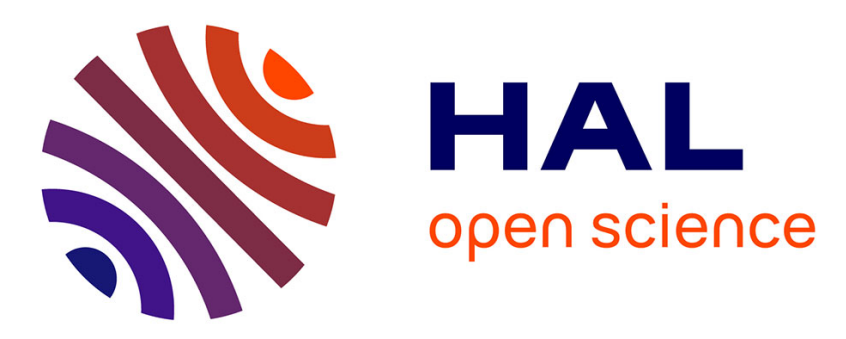

\title{
Insights from quantum chemical calculations into inner and outer-sphere complexation of plutonium(IV) by monoamide and carbamide extractants
}

Abdelmounaim Failali, Eléonor Acher, Valérie Vallet, Florent Réal, Dominique

Guillaumont

\section{To cite this version:}

Abdelmounaim Failali, Eléonor Acher, Valérie Vallet, Florent Réal, Dominique Guillaumont. Insights from quantum chemical calculations into inner and outer-sphere complexation of plutonium(IV) by monoamide and carbamide extractants. Physical Chemistry Chemical Physics, 2021, 23, pp.2229-2237. 10.1039/D0CP05363E . hal-03116082

\section{HAL Id: hal-03116082 \\ https://hal.science/hal-03116082}

Submitted on 5 Oct 2021

HAL is a multi-disciplinary open access archive for the deposit and dissemination of scientific research documents, whether they are published or not. The documents may come from teaching and research institutions in France or abroad, or from public or private research centers.
L'archive ouverte pluridisciplinaire HAL, est destinée au dépôt et à la diffusion de documents scientifiques de niveau recherche, publiés ou non, émanant des établissements d'enseignement et de recherche français ou étrangers, des laboratoires publics ou privés. 


\title{
PCCP
}

\section{ARTICLE TYPE}

Cite this: DOI: $00.0000 / x x x x x x x x x x$

Insights from quantum chemical calculations into inner and outersphere complexation of plutonium(IV) by monoamide and carbamide extractants

\author{
Abdelmounaim Failali, ${ }^{a, b}$ Eléonor Acher, $^{a}$ Valérie Vallet, ${ }^{b}$ Florent Réal, ${ }^{b}$ Dominique \\ Guillaumont $^{a}$
}

Received Date

Accepted Date

DOI: $00.0000 / x x x x x x x x x x$

The strong influence of the structure of amide derivatives on their extraction properties has been demonstrated in several studies in the literature. To rationalize and investigate this influence of the nature and length of the monoamide alkyl chains on $\mathrm{Pu}(\mathrm{IV})$ extraction/complexation, a theoretical study was performed using the Density Functional Theory (DFT) method in the scalar relativistic framework. For that, the geometries for the inner/outer-sphere complexes and interaction energies of $\left[\mathrm{Pu}\left(\mathrm{NO}_{3}\right)_{4}\right]$ and $\left[\mathrm{Pu}\left(\mathrm{NO}_{3}\right)_{6}\right]^{2-}$ with different ligands have been calculated. For both inner and outer-sphere complexes, it is found that the introduction of a bulky alkyl group on the carbonyl side strongly diminishes the complexation energy. This is fully consistent with monamide extraction properties. The influence of the bulkiness of the alkyl group is as or even more important for outer than for inner-sphere interactions. This result was unexpected when considering that there are less flexibility and stronger steric constraints in the inner sphere compared to the outer one. However, this can be attributed to specific electrostatic interactions between the two outer-sphere amide ligands and two nitrate ions of $\left[\mathrm{Pu}\left(\mathrm{NO}_{3}\right)_{6}\right]^{2-}$. By increasing the polarity of the solution, such interactions diminish and the outer-sphere ligands move away from $\left[\mathrm{Pu}\left(\mathrm{NO}_{3}\right)_{6}\right]^{2-}$. Consequently, the solvent effects were found to be very significant for outer-sphere complexation while rather small for innersphere complexation. This gives the key possibility to tune the substituent effect by changing the polarity of the solution. As for carbamide ligands, it was found that the weak interactions (dispersion) have remarkable effects on both inner and outer-sphere complexations.

\section{Introduction}

Amide derivatives represent an important class of molecules to recover selectively metal ions such as platinum-group metals, gold or $5 \mathrm{f}$ elements by solvent extraction.1 1 -4 Tertiary N,N-dialkyl amides are particularly well known for their strong extraction ability regarding uranium(VI) and plutonium(IV) and are regarded as a promising alternative extractant family to Tri-n-ButylPhosphate (TBP). [5] A key property of amide derivatives is that it is possible to co-extract uranium and plutonium from nitric acid solutions and to further achieve $\mathrm{U} / \mathrm{Pu}$ separation by decreasing the nitric acid concentration. $\frac{10}{10}$ More recently, it was shown that carbamides are also capable of achieving such U(VI) and Pu(IV)

\footnotetext{
${ }^{a}$ CEA, DES, ISEC, DMRC, Univ Montpellier, Marcoule, F-30207 Bagnols-sur-Ceze Cedex, France,E-mail: dominique.guillaumont@cea.fr

${ }^{a}$ Université Lille, CNRS, UMR 8523-PhLAM-Physique des Lasers, Atomes et Molécules, F-59000 Lille, France

$\uparrow$ Electronic Supplementary Information (ESI). Additional geometrical parameters. The Cartesian coordinates of all structures are available on the free platform Zenodo at the following link with DOI 10.5281/zenodo.4068222
}

extraction and separation. ${ }^{11}$ Because of their keen industrial interest, a large number of N,N-dialkylamides have been synthesized and an extensive database of $\mathrm{U}(\mathrm{VI})$ and $\mathrm{Pu}(\mathrm{IV})$ distribution ratio between organic and aqueous phases and U(VI)/Pu(IV) selectivity factors is available. $6[12,15$ The strong dependence of the extraction properties on the chemical conditions, namely nitric acid and extractant concentrations, has been established. $\underline{816}$ Moreover, one of their most interesting features is that it is possible to adjust their physicochemical and extraction properties by altering the alkyl chains on either nitrogen or carbonyl sides. Extraction properties are particularly influenced by the size and bulkiness of their alkyl groups adjacent to the carbonyl group. Variations of extraction properties are particularly strong for plutonium. 6817 This was first discovered in the 1960s by Siddall et al. ${ }^{6}$ This opens up the possibility to tune their extracting strength and selectivity toward metal ions by altering the length and branching of amide alkyl groups. Siddall et al. $\underline{6}$ have demonstrated that a simple modification of the acyl group can suppress $\mathrm{Pu}$ (IV) extraction. 18 In the series $\mathrm{R}=\mathrm{CH}_{3}, \mathrm{C}_{2} \mathrm{H}_{5}, \mathrm{CH}\left(\mathrm{CH}_{3}\right)_{2}$, $\mathrm{C}\left(\mathrm{CH}_{3}\right)_{3}, \mathrm{Pu}(\mathrm{IV})$ distribution ratio $D_{P u}$ continuously drops from 
$21\left(\mathrm{R}=\mathrm{CH}_{3}\right)$ to $0.001\left(\mathrm{R}=\mathrm{C}\left(\mathrm{CH}_{3}\right)_{3}\right)$, while $\mathrm{U}(\mathrm{VI})$ distribution coefficient decreases much less significantly from 9.9 to 0.6 (upon extraction from a $3 \mathrm{M}$ nitric acid aqueous solution to a toluene organic phase with $0.5 \mathrm{M}$ of amide extractant). 6 Accordingly, U/Pu separation factor increases from 0.5 to $\sim 600$. Since this early work, monoamides have been investigated extensively for the separation of hexa- and tetravalent actinide ions. Monoamides with long alkyl chains that prevent third phase formation have been developed. DEHiBA (N,N-di(2-ethylhexyl)isobutyramide) and DEHBA (N,N-di(2-ethylhexyl)butyramide) are probably the most investigated derivatives so far. ${ }^{8 / 9] 12] 15|21| 22}$ As reported for the earlier monoamides with shorter alkyl chains, the branching on the acyl group for DEHiBA suppress plutonium(IV) extraction compared to DEHBA.

Notwithstanding their industrial interest, the strong influence of N,N-dialkylamide structure on extracting properties is yet to be rationalized. To the best of our knowledge, there is no clear explanation for what makes the monoamide structure have such a great impact on the extraction ability. For decades, it was assumed that amide derivatives operate through a solvation mechanism as in the PUREX process with TBP,where $\mathrm{Pu}(\mathrm{IV})$ and $\mathrm{U}(\mathrm{VI})$ are predominantly extracted as the $\mathrm{Pu}\left(\mathrm{NO}_{3}\right)_{4} \mathrm{~L}_{2}$ and $\mathrm{UO}_{2}\left(\mathrm{NO}_{3}\right)_{2} \mathrm{~L}_{2}$ complexes in which two amide ligands bind Pu(IV) and U(VI) in the inner coordination sphere. ${ }^{8}$ The strong variations of the Pu distribution coefficient as a function of the bulkiness of the acyl group was attributed to steric hindrance in the Pu coordination sphere. However, recent studies have revealed that plutonium extraction with amide derivatives is more complex than with TBP.17/19 By coupling UV-Vis spectroscopy, EXAFS and quantum chemical calculations, it has been shown that the plutonium hexanitrato complex $\mathrm{Pu}\left(\mathrm{NO}_{3}\right)_{6}{ }^{2-}$ can also be extracted in the organic phase with no amide ligand present in the first coordination sphere. It was deduced that two protonated amide ligands bind in the outer coordination sphere to ensure the charge neutrality and the stability of the complex in the organic phase. However the detailed structure of the outer-sphere species is not known and could not be characterized from experimental data. It was shown that the $\mathrm{Pu}(\mathrm{IV})$ coordination structure can switch from inner to outer complexation either by varying the experimental conditions (such as nitric acid concentration) or by slightly altering the amide alkyl group.1923 25 Furthermore, the recent study of $\mathrm{Pu}(\mathrm{IV})$ with linear alkyl chains carbamides demonstrated that carbamides are strong extractants at high nitric acidity while promoting outersphere coordination. As a result, the strong variation of extraction properties cannot be solely rationalized from steric hindrance in the inner coordination sphere. As found for the recovery of gold with amides, outer-sphere interactions appear to be of primary importance. ${ }^{3}$ Thus, the understanding the relationship between the structure of the ligands and their extraction ability is crucial to design new extraction processes.

The aim of this work is to explore and rationalize $\mathrm{Pu}(\mathrm{IV})$ inner and outer-sphere interactions with amide and carbamide derivatives from scalar relativistic Density Functional Theory (DFT) calculations, that have proven to be reliable at predicting the geometries of Pu(IV) complexes. 24|26 28 While the structures of the inner-sphere complexes with amide and carbamide ligands have been well characterized in the solid state from XRD and in solution from EXAFS, the structures of outer-sphere complexes are largely unknown, though carbamides are believed to promote the formation of outer-sphere complexes. ${ }^{11}$ DFT geometry optimizations and complexation energetics shall help shedding light on their 3D structures and relative stabilities.

Herein, we consider that the ligands extract $\mathrm{Pu}(\mathrm{IV})$ from nitric acid according to the following reactions:

$$
\begin{gathered}
\mathrm{Pu}^{4+}(\mathrm{aq})+4\left(\mathrm{NO}_{3}\right)^{2-}(\mathrm{aq})+2 \mathrm{~L}(\mathrm{org}) \rightleftharpoons\left[\mathrm{Pu}\left(\mathrm{NO}_{3}\right)_{4} \mathrm{~L}_{2}\right](\mathrm{org}) \\
\mathrm{Pu}^{4+}(\mathrm{aq})+6\left(\mathrm{NO}_{3}\right)^{2-}(\mathrm{aq})+2 \mathrm{H}^{+}(\mathrm{aq})+2 \mathrm{~L}(\mathrm{org}) \rightleftharpoons\left[\mathrm{Pu}\left(\mathrm{NO}_{3}\right)_{6}\right](\mathrm{HL})_{2}(\mathrm{org})
\end{gathered}
$$

in which the complexing ligand is noted L; (aq) and (org) stand for the aqueous and the organic phases, respectively. Reaction 11 corresponds to the formation of an inner-sphere complex $\left[\mathrm{Pu}\left(\mathrm{NO}_{3}\right)_{4} \mathrm{~L}_{2}\right]$ (org) with four bidentate nitrate anions and two ligands. Reaction 2 corresponds to the formation a Pu(VI)hexanitrato core $\mathrm{Pu}\left(\mathrm{NO}_{3}\right)_{6}{ }^{2-}$ which is charge balanced by protonated $\mathrm{HL}^{+}$attached by hydrogen bonds (outer-sphere complexation). Note that we disregard the more hypothetical possibility of forming a complex with a hybrid coordination $\mathrm{Pu}\left(\mathrm{NO}_{3}\right)_{5} \mathrm{~L}(\mathrm{HL})$, corresponding to $\mathrm{Pu}\left(\mathrm{NO}_{3}\right)_{5} \mathrm{~L}^{-}$with one $\mathrm{HL}^{+}$protonated ligand hydrogen-bonded to one nitrate ion.

To rationalize the influence of the alkyl groups on $\mathrm{Pu}(\mathrm{IV})$ complexation, the nature of the alkyl groups in the monoamide $\left(R_{1}\right.$ $\mathrm{R}_{3}$ ) and the carbamide $\left(\mathrm{R}_{1}-\mathrm{R}_{4}\right)$ ligands drawn in Figure 1 have been systematically varied following the list and labelling given in Table 1. PEE and IEE ligands can be considered as model ligands for the two isomeric DEHBA and DEHiBA monoamides.
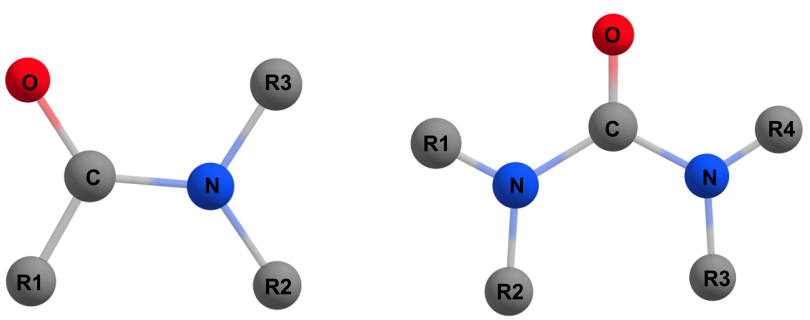

Fig. 1 Labelling of the $R_{1}, R_{2}, R_{3}$ and $R_{4}$ alkyl groups in the monoamide (left) and carbamide (right) ligands, as listed in Table 1

Table 1 List of aliases for the substituted monoamide and carbamide ligands.

\begin{tabular}{lcccc}
\hline Ligands & $\mathrm{R}_{1}$ & $\mathrm{R}_{2}$ & $\mathrm{R}_{3}$ & $\mathrm{R}_{4}$ \\
\hline MMM & $\mathrm{CH}_{3}$ & $\mathrm{CH}_{3}$ & $\mathrm{CH}_{3}$ & - \\
EMM & $\mathrm{C}_{2} \mathrm{H}_{5}$ & $\mathrm{CH}_{3}$ & $\mathrm{CH}_{3}$ & - \\
MME & $\mathrm{CH}_{3}$ & $\mathrm{CH}_{3}$ & $\mathrm{C}_{2} \mathrm{H}_{5}$ & - \\
MEE & $\mathrm{CH}_{3}$ & $\mathrm{C}_{2} \mathrm{H}_{5}$ & $\mathrm{C}_{2} \mathrm{H}_{5}$ & - \\
EEE & $\mathrm{C}_{2} \mathrm{H}_{5}$ & $\mathrm{C}_{2} \mathrm{H}_{5}$ & $\mathrm{C}_{2} \mathrm{H}_{5}$ & - \\
PEE & $\mathrm{C}_{3} \mathrm{H}_{7}$ & $\mathrm{C}_{2} \mathrm{H}_{5}$ & $\mathrm{C}_{2} \mathrm{H}_{5}$ & - \\
IEE & $\mathrm{CH}_{\left(\mathrm{CH}_{3}\right)_{2}}$ & $\mathrm{C}_{2} \mathrm{H}_{5}$ & $\mathrm{C}_{2} \mathrm{H}_{5}$ & - \\
C4M & $\mathrm{CH}_{3}$ & $\mathrm{CH}_{3}$ & $\mathrm{CH}_{3}$ & $\mathrm{CH}_{3}$ \\
C4E & $\mathrm{C}_{2} \mathrm{H}_{5}$ & $\mathrm{C}_{2} \mathrm{H}_{5}$ & $\mathrm{C}_{2} \mathrm{H}_{5}$ & $\mathrm{C}_{2} \mathrm{H}_{5}$ \\
\hline
\end{tabular}




\section{Computational Methods}

All molecular geometries have been fully optimized using the Gaussian quantum chemistry package at the DFT level, 29 employing the PBE0 functional,, 30 that has been shown to yield accurate structural parameters of the $\left[\mathrm{Pu}\left(\mathrm{NO}_{3}\right)_{6}\right]^{2-}$ complex. ${ }^{[28131}$ For each ligand, 4 to 10 initial conformations for $\left[\mathrm{Pu}\left(\mathrm{NO}_{3}\right)_{4} \mathrm{~L}_{2}\right]$ and $\left[\mathrm{Pu}\left(\mathrm{NO}_{3}\right)_{6}\right]\left(\mathrm{HL}_{2}\right)$ complexes were constructed and optimized in the gas phase in order to determine the lowest energy structure. Def2-TZVP basis set has been used for light atoms (H, N, O, and C). .32 For plutonium, the 82 inner-shell core electrons were replaced by the relativistic 5f-in-core large-core pseudopotential (LPP) noted ECP82MWB, 33 together with the corresponding valence basis set ECP82MWB-AVTZ. ${ }^{33}$ The use of an LPP for actinides eliminates the difficulties arising from the open 5f-shells ( $5 f^{4}$ valence configuration for $\mathrm{Pu}(\mathrm{IV})$ ) that may yield a multireference character for the ground state with spin contamination issues. It is also trustworthy as it offers satisfactory results for actinide-ligand bond distances and binding energies, with deviations to small-core results not larger than $0.025 \AA$ (1.2\%), and $0.92 \mathrm{eV}(0.6 \%)$, for actinocene complexes. ${ }^{34}$ To confirm the applicability of LPP to our systems, test calculations were performed using a plutonium small-core pseudopotential noted ECP60MWB and accompanying basis set. $\frac{35}{35}$ Energy variations for reaction (1) and (2) are compared in Table S1 in S.I. section. The values differ by less than $5 \mathrm{~kJ} \mathrm{~mol}^{-1}$ and confirm the judicious choice of a 5 f-in-core pseudopotential for the systems of interest.

Core polarization effects described through a core-polarization potential (CPP) were shown to be small ${ }^{33}$ and can be safely disregarded. We have also neglected spin-orbit as Šulka et al. ${ }^{[28}$ found a small effect of $0.014 \AA$ on the $\mathrm{Pu}-\mathrm{O}_{\mathrm{NO}}$ bond lengths in the $\mathrm{Pu}(\mathrm{IV})$-hexanitrato complex. Furthermore, as we are interested in relative complexation energies, we can forecast that the absolute errors induced by neglecting core-polarization effects and spin-orbit coupling will compensate when taking energy differences.

When calculating the relative complexation free energies for various monoamide or carbamide ligands, it is relevant to account for long-range dispersion contributions, that might be sizable in the outer-sphere complexes $\left(\left[\mathrm{Pu}\left(\mathrm{NO}_{3}\right)_{6}\right](\mathrm{HL})_{2}\right.$ (org)). We have thus performed single-point energy calculations with two approaches (i) by adding to the PBE0 energies the Grimme's DFTD3 dispersion correction ${ }^{36}$; (ii) by using the MP2 wave-function based method as implemented in the Turbomole quantum chemistry package. ${ }^{37}$ The later calculations used aug-cc-pVTZ ${ }^{38}$ basis sets for the light atoms, keeping the 1s core electrons frozen, and the ECP82MWB-AVTZ ${ }^{33}$ basis set for $\mathrm{Pu}$, together with the resolution of identity ${ }^{39}$ with the corresponding auxiliary basis sets. ${ }^{32}$.

To mimic experimental conditions, in which the Pu metal ions are extracted into an organic phase that contains the extractant molecules, nitric acid and aliphatic solvent, the impact of solvation effects on the complex geometries and relative complexation energies was explored using the Polarizable Continuum solvation Model (PCM) as implemented in Gaussian package (See Ref . 40 for a review on solvation models), for two solvents $n$-dodecane $\left(\varepsilon_{r}=2.02\right)$ and Dimethylacetamide DMA $\left(\varepsilon_{r}=37.78\right)$.
Vibrational frequencies calculation for the ligands and complexes were performed to verify that the geometries were minima, and to compute the zero-point energies and thermal corrections at $298.15 \mathrm{~K}$ using the rigid rotor-harmonic oscillator approximation, as implemented in Gaussian, either in the gas phase or in solution.

Finally, the affinities of the model extractants are compared by calculating the free energies of the following ligand-exchange reactions:

$$
\begin{aligned}
{\left[\mathrm{Pu}\left(\mathrm{NO}_{3}\right)_{4}(\mathbf{L} \mathbf{1})_{2}\right]+2 \mathbf{L} 2 } & \rightleftharpoons\left[\mathrm{Pu}\left(\mathrm{NO}_{3}\right)_{4}(\mathbf{L} 2)_{2}\right]+2 \mathbf{L} \mathbf{1} \\
{\left[\mathrm{Pu}\left(\mathrm{NO}_{3}\right)_{6}\right](\mathrm{HL} \mathbf{1})_{2}+2 \mathbf{L} 2 } & \rightleftharpoons\left[\mathrm{Pu}\left(\mathrm{NO}_{3}\right)_{6}\right](\mathrm{HL} 2)_{2}+2 \mathbf{L} \mathbf{1}
\end{aligned}
$$

For instance the relative complexation free energy $\Delta \Delta G$ reads:

$$
\Delta \Delta G=G\left(\mathrm{Pu}_{\mathrm{NO}_{3}} \mathbf{L} \mathbf{2}\right)-G\left(\mathrm{Pu}_{\mathrm{NO}_{3}} \mathbf{L} \mathbf{1}\right)-2(G(\mathbf{L} \mathbf{2})-G(\mathbf{L} \mathbf{1}))
$$

\section{Results and Discussion}

All Pu(IV) complexes with amide ligands reported in Table 1 were considered. The calculations were performed in the gas phase for all the ligands and in solution for some selected ligands. In the industrial process, the organic phase contains extractant molecules in an aliphatic solvent. After contact with the acidic aqueous phase, some amount of extracted nitric acid is also present in the organic phase. $n$-dodecane is the best model for the aliphatic solvent but the presence of amides and nitric acid is expected to increase the polarity of the solution. Therefore, the DMA solvent model was also used to investigate the effect of increasing the polarity of the solution.

\section{Inner-sphere complexation with monoamides}

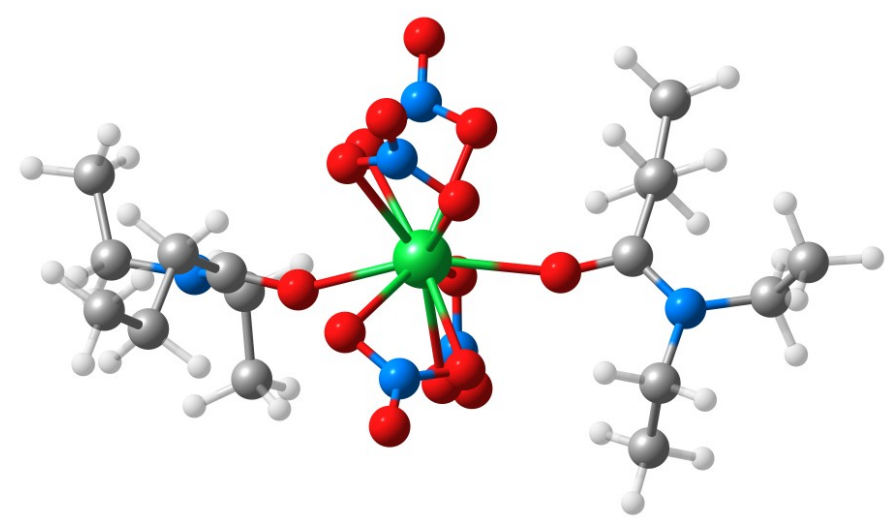

Fig. 2 Geometry of the inner-sphere $\mathrm{Pu}\left(\mathrm{NO}_{3}\right)_{4}(\mathrm{~L})_{2}$ complex with the PEE ligand optimized in the gas phase.

The optimized structure of $\left[\mathrm{Pu}\left(\mathrm{NO}_{3}\right)_{4} \mathrm{~L}_{2}\right]$ is represented in Figure 2 for PEE ligand and structural parameters are listed in Table 2 for all the ligands. Additional structural parameters are given in the ESI. In the most stable geometry of these systems, the coordination number of plutonium is 10 , with the nitrate groups acting as bidentate ligands. Amide ligands act as monodentate ligands, which interact with plutonium through the carbonyl oxygen. Changing the ligand alkyl chains does not signifi- 
cantly alter the structure. In the gas phase, the $\mathrm{Pu}-\mathrm{O}_{\mathrm{L}}$ distance varies from $2.34 \AA$ to $2.35 \AA$ while the mean value of $\mathrm{Pu}-\mathrm{O}_{\text {nit }}$ varies from $2.47 \AA$ to $2.49 \AA$. Ligand interatomic distances, such as $\mathrm{C}-\mathrm{O}$ or $\mathrm{C}-\mathrm{N}$ distances, also remain similar for all the ligands. In the polar DMA solvent $\mathrm{Pu}-\mathrm{O}_{\mathrm{L}}$ distances are shortened by $0.03-0.04 \AA$ compared to the gas phase while $\mathrm{Pu}-\mathrm{O}_{\text {nit }}$ distances are lengthened by $0.02-0.03 \AA$. These calculated distances are all longer than the solid-phase distances reported from XRD of $2.26 \AA$ and $2.44 \AA$ respectively for $\mathrm{Pu}-\mathrm{O}_{\mathrm{L}}$ and $\mathrm{Pu}-\mathrm{O}_{\text {nit }}$ distances in the $\mathrm{Pu}(\mathrm{IV})$-tetranitrate complex with $\mathrm{N}, \mathrm{N}$-dibutyl-butanamide (DBBA). 19

Table 2 Selected interatomic distances (average values in $\AA$ ) in the $\left[\mathrm{Pu}\left(\mathrm{NO}_{3}\right)_{4} \mathrm{~L}_{2}\right]$ complexes optimized in the gas phase and within a solvent.

\begin{tabular}{lccccc}
\hline Ligand & $d_{\mathrm{Pu}-\mathrm{O}_{\mathrm{L}}}$ & $d_{\mathrm{Pu}-\mathrm{O}_{\text {nit }}}$ & $d_{\mathrm{Pu}-\mathrm{N}_{\mathrm{nit}}}$ & $d_{\mathrm{O}-\mathrm{C}}$ & $d_{\mathrm{C}-\mathrm{N}}$ \\
\hline \multicolumn{7}{l}{ gas phase } \\
MMM & 2.352 & 2.474 & 2.932 & 1.250 & 1.327 \\
EMM & 2.347 & 2.477 & 2.931 & 1.250 & 1.328 \\
$\mathrm{MME}$ & 2.356 & 2.483 & 2.930 & 1.249 & 1.327 \\
$\mathrm{MEE}$ & 2.354 & 2.480 & 2.931 & 1.250 & 1.327 \\
EEE & 2.348 & 2.485 & 2.933 & 1.251 & 1.326 \\
$\mathrm{PEE}$ & 2.347 & 2.483 & 2.934 & 1.252 & 1.327 \\
$\mathrm{IEE}$ & 2.343 & 2.486 & 2.937 & 1.252 & 1.327 \\
n-dodecane solvent & & & & \\
MMM & 2.337 & 2.489 & 2.934 & 1.252 & 1.325 \\
EEE & 2.332 & 2.495 & 2.940 & 1.256 & 1.323 \\
PEE & 2.332 & 2.495 & 2.940 & 1.257 & 1.323 \\
IEE & 2.327 & 2.498 & 2.943 & 1.256 & 1.325 \\
DMA solvent & & & & \\
MMM & 2.313 & 2.508 & 2.941 & 1.259 & 1.319 \\
EEE & 2.315 & 2.506 & 2.942 & 1.261 & 1.320 \\
PEE & 2.315 & 2.506 & 2.942 & 1.261 & 1.320 \\
IEE & 2.300 & 2.513 & 2.962 & 1.263 & 1.320 \\
\hline
\end{tabular}

The variation of the complexation free energies between the ligands and the tetra-nitrate plutonium core complex are reported in Table 3 . As detailed in the computational methods section, the free energies are given as ligand-exchange complexation free energies defined by Eq. 5. The latter were also calculated adding the D3 empirical correction to account for dispersion interactions. On the carbonyl side, substituting the methyl by an ethyl group in $\mathrm{R}_{1}$ position (from MMM to EMM or from MEE to EEE) has a small destabilizing effect $\left(+7 \mathrm{~kJ} \mathrm{~mol}^{-1}\right)$ which nearly disappears with dispersion corrections at the D3 level. Lengthening the alkyl chain further from ethyl to $n$-propyl stabilizes the complex at both levels of calculation (EEE $\rightarrow$ PEE). Conversely, increasing the branching from $n$-propyl to iso-propyl destabilizes strongly the complexation and has the most significant effect. On the nitrogen side, in $R_{2}$ and $R_{3}$ positions, substituting only one methyl into one ethyl has a small destabilizing effect while further changing the second methyl group into ethyl has the reverse stabilizing effect. The inclusion of D3 dispersion correction systematically increases the stability of the complexation with longer alkyl chains by a few $\mathrm{kJ} \mathrm{mol}^{-1}$ as given by the comparison between PBE0 and PBE0-D3 results. This is indicative of the dispersion interactions induced by alkyl groups.

If we focus on PEE and IEE, which can be considered as model
Table 3 Free energy variations corresponding to the inner-sphere ligand exchange reaction (3), in $\mathrm{kJ} \mathrm{mol}^{-1}$, calculated in the gas phase at the PBEO and PBEO-D3 levels of theory.

\begin{tabular}{llcc}
\hline & L1 $\rightarrow$ L2 & PBE0 & PBE0-D3 \\
\hline $\mathrm{R}_{1}$ & $\mathrm{MMM} \rightarrow$ EMM & 7 & 2 \\
& $\mathrm{MEE} \rightarrow$ EEE & 7 & -2 \\
& $\mathrm{EEE} \rightarrow$ PEE & -5 & -9 \\
& $\mathrm{PEE} \rightarrow$ IEE & 22 & 14 \\
\hline $\mathrm{R}_{2}, R_{3}$ & $\mathrm{MMM} \rightarrow$ MME & -3 & -4 \\
& $\mathrm{MME} \rightarrow$ MEE & -4 & -5 \\
\hline
\end{tabular}

ligands for DEHBA (N,N-di(2-ethylhexyl)butyramide) and DEHiBA (N,N-di(2-ethylhexyl)isobutyramide) that have been largely studied for $\mathrm{U}(\mathrm{VI})$ and $\mathrm{Pu}(\mathrm{IV})$ extraction, $\underline{818}$ we can observe $\mathrm{a}+22 \mathrm{~kJ} \mathrm{~mol}^{-1}$ free energy difference at the PBE0 level and $+14 \mathrm{~kJ} \mathrm{~mol}^{-1}$ at the PBE0-D3 level. For these two isomeric ligands, calculations at the MP2 level and with the $n$-dodecane and DMA solvent models were also performed. As the ligand-exchange complexes are of comparable shape and size, the errors associated with the solvent model are expected to largely cancel out. The relative complexation free energies between PEE and IEE are given in Table 4. The $+22 \mathrm{~kJ} \mathrm{~mol}^{-1}$ free energy difference calculated in the gas phase is slightly decreased in solution, by $6 \mathrm{~kJ} \mathrm{~mol}^{-1}$ in $n$ dodecane and by $10 \mathrm{~kJ} \mathrm{~mol}^{-1}$ in the more polar DMA solvent. The MP2 values give a slightly lower free energy difference than PBE0, but they are consistent with the PBE-D3 results, making us confident on the capability of the D3 correction in capturing dispersion effects. Thus, only the latter method will be used for outer-sphere complexes. According to the calculations, the free energy variation systematically indicates a less favorable complexation for the branched alkyl group than for the linear alkyl one in the case of $\left[\mathrm{Pu}\left(\mathrm{NO}_{3}\right)_{4} \mathbf{L}_{2}\right]$ formation. These results are consistent with the sharp diminution of the distribution ratio moving from DEHBA to DEHiBA observed experimentally for Pu(IV) extraction at low nitric acidity where the inner-sphere complex is the predominant species. $\frac{12}{12}$ They confirm the destabilizing steric hindrance effect, induced by the presence of voluminous branched alkyl group at the amide $\mathrm{R}_{1}$ moiety, on plutonium tetranitrate complexation.

Table 4 Variation of the complexation free energies for the formation of $\left[\mathrm{Pu}\left(\mathrm{NO}_{3}\right)_{4} \mathrm{~L}_{2}\right]$ when going from the PEE to the IEE ligand. All values are in $\mathrm{kJ} \mathrm{mol}^{-1}$ and were calculated in the gas phase and in solution.

\begin{tabular}{lc}
\hline & $\Delta \Delta G(\mathrm{PEE} \rightarrow \mathrm{IEE})$ \\
\hline Gas PBE0 & 22 \\
Gas PBE0-D3 & 14 \\
Gas MP2 & 14 \\
Dodecane PBE0 & 16 \\
DMA PBE0 & 12 \\
\hline
\end{tabular}

\section{Outer-sphere complexation with monoamides}

In the outer-sphere $\mathrm{Pu}\left(\mathrm{NO}_{3}\right)_{6}(\mathrm{HL})_{2}$ structures, the interaction of the amide ligands with plutonium nitrates complexes occurs via strong hydrogen bonds between protonated amides $\mathrm{HL}^{+}$and oxy- 

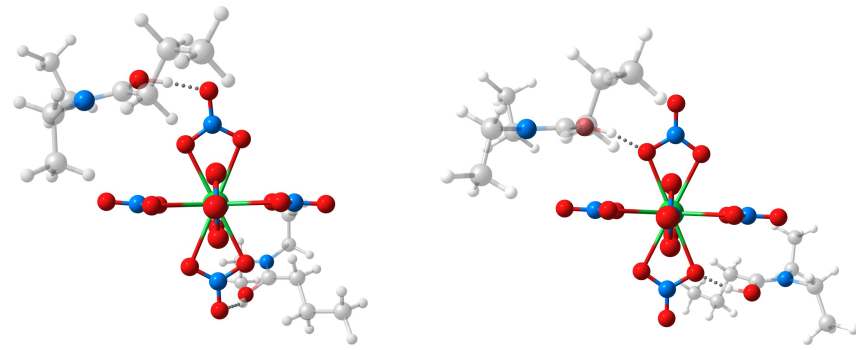

Fig. 3 Gas-phase optimized geometries of the outer-sphere $\left[\mathrm{Pu}\left(\mathrm{NO}_{3}\right)_{6}\right](\mathrm{HPEE})_{2}$ complex in the geometries I (left) and II (right).

gen nitrate ions. The coordination number of plutonium is twelve with six bidentate nitrate ions in the first coordination sphere and the two protonated amides form hydrogen bonds with nitrate ions in the outer coordination sphere. Two possible hydrogen bonds interactions were considered resulting in two different geometries described in Figure 3 for PEE ligand. In the first geometry (I), hydrogen bonds are formed with oxygen nitrate of the outer sphere. This structure was described in our previous work. $\frac{19}{1 n}$ geometry II, hydrogen atoms are bound to nitrate oxygen atoms that are also coordinated to plutonium. This coordination mode can be deduced from the electrostatic potential which was determined for $\mathrm{Pu}\left(\mathrm{NO}_{3}\right)_{6}{ }^{2-}$ anion. ${ }^{41]}$ It was shown that first-shell oxygen atoms may be considered as possible acceptor sites for non-covalent interactions even though such interactions were not observed in the crystal structure with pyridinium cations. ${ }^{41}$ In addition, such a coordination mode has been shown to exist for uranyl sulfate complexes with tertiary amines. Hydrogen bonds between the protonated amines and coordinated oxygen sulfate atoms were found in the solid-state crystal structure $\frac{42}{42}$ and in $n$-dodecane from molecular dynamics simulations. ${ }^{.43}$ According to our DFT calculations, geometry II is significantly more stable than geometry I both in the gas phase and in solution (See Table 55) for all the ligands except MMM. For the latter, geometries I and II are found energetically degenerate in the gas phase $(\Delta G=$ $1 \mathrm{~kJ} \mathrm{~mol}^{-1}$ ) while geometry II is relatively stabilized by $14 \mathrm{~kJ} \mathrm{~mol}^{-1}$ and $22 \mathrm{~kJ} \mathrm{~mol}^{-1}$ in $n$-dodecane and DMA solvents, respectively.

Table 5 Free energy differences between the two outer-sphere geometries I and II for the $\left[\mathrm{Pu}\left(\mathrm{NO}_{3}\right)_{6}\right]\left(\mathrm{HL}_{2}\right)$ monoamide complexes. The values are in $\mathrm{kJ} \mathrm{mol}^{-1}$ and were calculated in the gas phase, in $n$-dodecane (Dod.) and in DMA solvents.

\begin{tabular}{lccccccc}
\hline Ligand & MMM & EMM & MME & MEE & EEE & PEE & IEE \\
\hline Gas PBE0 & 1 & -17 & -5 & -11 & -20 & -22 & -17 \\
Gas PBE0-D3 & 1 & & -4 & & -20 & -23 & -18 \\
Dod. PBE0 & -14 & & & & -24 & -23 & -26 \\
DMA PBE0 & -22 & & & & -13 & -23 & -26 \\
\hline
\end{tabular}

In both outer-sphere geometries I and II, the proton is located on the carbonyl group rather than on a nitrate anion. In the gas phase, the protonated ligands wrap the hexanitrato plutonium complex. Calculated interatomic distances are listed in the ESI for geometry I and reported in Table 6 for the most stable geometry II. For the latter the inner $\mathrm{Pu}\left(\mathrm{NO}_{3}\right)_{6}{ }^{2-}$ coordination shell is marginally altered by the nature of the outer-sphere ligand.
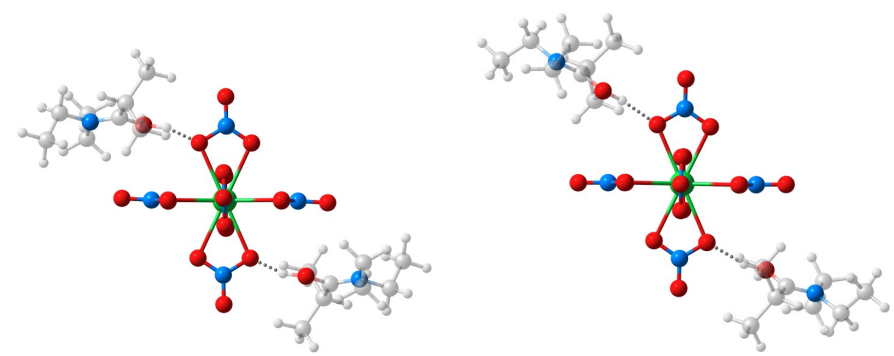

Fig. 4 Perspective views of the outer-sphere complex $\left[\mathrm{Pu}\left(\mathrm{NO}_{3}\right)_{6}\right](\mathrm{HIEE})_{2}$ in geometry II optimized in the gas phase (left) and in DMA solvent (right).

In all complexes, the average $\mathrm{Pu}-\mathrm{O}$ distance to the nitrate anions which are not involved in hydrogen bonding $\left(\mathrm{Pu}-\mathrm{O}_{\text {nit1 }}\right)$ is $2.52 \AA$. This distance is close to the average value reported in the $\mathrm{Pu}\left(\mathrm{NO}_{3}\right)_{6}{ }^{2-}$ crystal structures $(2.49 \AA) .44$ The average distance between $\mathrm{Pu}$ and the nitrate oxygens involved in the hydrogen bonds $\left(\mathrm{Pu}-\mathrm{O}_{\text {nit2 }}\right)$ is $0.04-0.05 \AA$ longer than the distance to the other nitrate oxygens $\left(\mathrm{Pu}-\mathrm{O}_{\text {nit1 }}\right)$. The longest $\mathrm{Pu}-\mathrm{O}_{\text {nit2 }}$ distance is found with IEE ligand. The lengths of the hydrogen bonds between the nitrate anions and the protonated ligand increase with the lengthening of the alkyl group in any of the $\mathrm{R}_{1}, \mathrm{R}_{2}$ or $\mathrm{R}_{3}$ positions, as indicated from $\mathrm{O}_{\text {nit }}-\mathrm{O}_{\mathrm{L}}$ and $\mathrm{O}_{\mathrm{L}}-\mathrm{H}$ distances. On the contrary, the hydrogen bond distance decreases from $n$-propyl to iso-propyl. This could indicate a stronger $\mathrm{H}$-bond but the $\mathrm{OHO}$ angle also diminishes from $164^{\circ}$ to $160^{\circ}$. This may indicate that the hydrogen bond is more constrained with IEE ligands. Another geometric difference arises from the position of the two amide groups in the complexes. In the gas-phase structures, each planar amide group is nearly parallel to one of the six trigonal planar nitrate anions (Figure 3) except with the bulky isopropyl group. As depicted in Figure 4 , with IEE the planar orientation of the amide group deviates from the parallel orientation with the planar nitrate ion. As a consequence the distance between $\mathrm{Pu}$ and the nitrogen atom of the amide function $\left(\mathrm{Pu}-\mathrm{N}_{\mathrm{L}}\right)$ increases by about $0.4 \AA$ for IEE compared to other ligands in the gas phase. As shown in the optimized structures, a number of short interatomic close-contacts are found between $\mathrm{C}-\mathrm{H}$ and $\mathrm{NO}_{3}{ }^{-}$oxygen atoms $(<2.80 \AA$ ), involving the $\mathrm{C}-\mathrm{H}$ groups from alkyl chains of both nitrogen and carbonyl sides.

The inclusion of solvent effects does not alter the plutoniumoxygen distances in the inner sphere but modifies the outersphere structure. Indeed, the two outer-shell ligands remain hydrogen bonded by the protonated amide group but move away from $\mathrm{Pu}\left(\mathrm{NO}_{3}\right)_{6}{ }^{2-}$. This effect amplifies with the solvent dielectric constant. As a consequence, the $\mathrm{Pu}-\mathrm{N}_{\mathrm{L}}$ distances increase by $\simeq 0.2 \AA$ in $n$-dodecane and by $\simeq 0.9 \AA$ in DMA compared to the gas phase except for IEE. The solvent effect is weaker for IEE ligands because the deviation of the amide group from the parallel planar orientation is already strong in the gas phase. The hydrogen bond distance increases slightly in dodecane (by $0.04 \AA$ to $0.07 \AA$ ) and strongly in DMA (by $0.13 \AA$ to $0.22 \AA$ ). The largest increase corresponds to IEE ligands.

The complexation energies were calculated for the ligand exchange reaction (4) corresponding to the formation of 
Table 6 Selected interatomic distances (average values $d$ in $\AA)^{a}$ and hydrogen bond angle $\left(\alpha_{\mathrm{O}-\mathrm{H}-\mathrm{O}}\right)$ in ${ }^{\circ}$ calculated in the $\left[\mathrm{Pu}\left(\mathrm{NO}_{3}\right)_{6}\right]\left(\mathrm{HL}_{2}\right)$ complex in geometry II optimized the gas phase and in solution.

\begin{tabular}{lcccccc}
\hline & $d_{\mathrm{Pu}-\mathrm{O}_{\text {nit1 }}}$ & $d_{\mathrm{Pu}-\mathrm{O}_{\text {nit }}}$ & $d_{\mathrm{Pu}-\mathrm{N}_{\mathrm{L}}}$ & $d_{\mathrm{O}_{\text {nit } 2}-\mathrm{O}_{\mathrm{L}}}$ & $d_{\mathrm{O}_{\text {nit }}-\mathrm{H}}$ & $\alpha_{O H O}$ \\
\hline gas & & & & & & \\
MMM & 2.524 & 2.565 & 5.973 & 2.504 & 1.506 & 163 \\
EMM & 2.523 & 2.566 & 6.031 & 2.511 & 1.513 & 164 \\
MME & 2.524 & 2.564 & 6.031 & 2.511 & 1.515 & 164 \\
MEE & 2.524 & 2.564 & 6.006 & 2.517 & 1.521 & 164 \\
EEE & 2.523 & 2.566 & 6.047 & 2.522 & 1.528 & 164 \\
PEE & 2.523 & 2.565 & 6.085 & 2.524 & 1.530 & 164 \\
IEE & 2.520 & 2.573 & 6.363 & 2.498 & 1.514 & 160 \\
solution & -dodecane & & & & \\
MMM & 2.524 & 2.562 & 6.178 & 2.546 & 1.555 & 165 \\
EEE & 2.524 & 2.562 & 6.210 & 2.558 & 1.570 & 165 \\
PEE & 2.524 & 2.562 & 6.232 & 2.559 & 1.571 & 165 \\
IEE & 2.523 & 2.567 & 6.551 & 2.546 & 1.585 & 158 \\
solution & DMA & & & & & \\
MMM & 2.524 & 2.560 & 6.856 & 2.644 & 1.651 & 174 \\
EEE & 2.524 & 2.560 & 6.811 & 2.650 & 1.660 & 173 \\
PEE & 2.524 & 2.561 & 6.840 & 2.654 & 1.664 & 172 \\
IEE & 2.525 & 2.559 & 6.993 & 2.666 & 1.732 & 156 \\
\hline
\end{tabular}

${ }^{a} O_{\text {nit } 1}$ denotes oxygen from nitrate ions which are not involve in hydrogen bond. $O_{\text {nit2 }}$ denotes oxygen from nitrate ions which are involved in hydrogen bond.

Table 7 Free energies variations corresponding to the outer-sphere ligand exchange reaction (4). The values are in $\mathrm{kJ} \mathrm{mol}^{-1}$ and were calculated in the gas phase.

\begin{tabular}{llcc}
\hline & L1 $\rightarrow$ L2 & PBE0 & PBE0-D3 \\
\hline $\mathrm{R}_{1}$ & $\mathrm{MMM} \rightarrow$ EMM & 3 & -1 \\
& $\mathrm{MEE} \rightarrow$ EEE & 3 & -3 \\
& $\mathrm{EEE} \rightarrow$ PEE & -6 & -11 \\
& $\mathrm{PEE} \rightarrow$ IEE & 34 & 39 \\
\hline $\mathrm{R}_{2}, \mathrm{R}_{3}$ & $\mathrm{MMM} \rightarrow \mathrm{MME}$ & -6 & -10 \\
& $\mathrm{MME} \rightarrow \mathrm{MEE}$ & -3 & 0 \\
\hline
\end{tabular}

$\left[\mathrm{Pu}\left(\mathrm{NO}_{3}\right)_{6}\right](\mathrm{HL2})_{2}$ relative to $\left[\mathrm{Pu}\left(\mathrm{NO}_{3}\right)_{6}\right](\mathrm{HL} 1)_{2}$. Calculated values are reported in Table 7 for the most stable geometry II. On the carbonyl side, in $\mathrm{R}_{1}$ position, substituting the methyl by an ethyl group or an ethyl by a $n$-propyl has very similar effects than those determined for inner-sphere complexation. Changing from MMM to EMM and MEE to EEE has a small destabilizing effect that is reversed when D3 dispersion corrections are included. From EEE to PEE, a stabilizing effect is calculated at both levels of calculations. Increasing the branching from $n$-propyl to isopropyl has a strong destabilizing effect $\left(\Delta \Delta G_{\text {Gas }}=39 \mathrm{~kJ} \mathrm{~mol}^{-1}\right.$ at the PBE0-D3 level). Such a destabilizing effect was also found for inner complexation but is unexpectedly much larger for this coordination mode while steric hindrance is expected to be smaller in the outer coordination sphere.

On the nitrogen side, the effects are different than those found for inner complexation. Substituting one methyl by in an ethyl group has a strong stabilizing effect up to $19 \mathrm{~kJ} \mathrm{~mol}^{-1}$ from MMM to MME at the PBE0-D3 level. Such effect was not found for innersphere complexation. The further addition of one ethyl group has no significant effect.
As for inner-sphere complexes, the complexation energy in the solvent phase was calculated for isomeric PEE and IEE derivatives. Relative energies in the gas phase and in solution are given in Table 8. The free energy difference between the two ligands is similar in the gas phase and in $n$-dodecane but decreases from $34 \mathrm{~kJ} \mathrm{~mol}^{-1}$ in the gas phase to $14 \mathrm{~kJ} \mathrm{~mol}^{-1}$ in the more polar DMA solution. These energy variations follow the structural changes from the gas phase to a polar solution with the diminution of close-contact interactions between $\mathrm{C}$-H groups and the nitrate anions. The energy difference between PEE and IEE is significant and is consistent with the sharp diminution that has been measured for $\mathrm{Pu}(\mathrm{IV})$ distribution ratio from DEHBA to DEHiBA in high nitric acid concentration. The solvent effect is more significant for outer than inner-sphere complexation. This is consistent with solvent effects which are stronger on the outer-sphere structure. In the gas phase, the preferred conformation of the outersphere complex with nearly parallel nitrate and amide groups is disfavored with the bulky IEE. In polar solution, the ligands move away and steric constraints become smaller.

Table 8 Variation of the complexation free energies for the formation of the $\left[\mathrm{Pu}\left(\mathrm{NO}_{3}\right)_{6}(\mathrm{HL})_{2}\right]$ complex when going from PEE to IEE ligands. The values are in $\mathrm{kJ} \mathrm{mol}^{-1}$ and were calculated in the gas phase and in solvent.

\begin{tabular}{llc}
\hline & PBE0 & PBE0-D3 \\
\hline Gas phase & 34 & 39 \\
Dodecane & 29 & 35 \\
DMA & 14 & 19 \\
\hline
\end{tabular}

\section{Complexation with carbamides}

On the one hand, a carbamide is considered as being more basic than an amide function and is expected to bind a metal cation more strongly. The calculated proton affinities confirm the stronger electron donor capability of the carbonyl oxygen in carbamides compared to amides (See Table S1 in the ESI). On the other hand, tetra-alkyl carbamides are bulkier than tri-alkyl monoamides for similarly sized-alkyl groups and are expected to induce larger steric hindrance effect in the plutonium coordination sphere. In the present work, inner and outer-sphere complexations were investigated for two carbamide derivatives with methyl and ethyl groups (C4M and C4E).

In the inner-sphere carbamide complexes, the plutoniumoxygen bond distances are close to those calculated with monoamides within $0.02 \AA$ (Table 9). The $\mathrm{Pu}-\mathrm{O}_{\mathrm{L}}$ distance is slightly shorter with $\mathrm{C} 4 \mathrm{M}$ than with any other monoamides while $\mathrm{Pu}-\mathrm{O}_{\mathrm{L}}$ distance with C4E is the longest one. This is an indication of the competition between electronic donor and steric hindrance effects.

For the outer-sphere complexation, the energy differences between geometries I and II are not as large as for monoamides (see Table 11). At the PBE0 level, the preferred coordination mode is geometry I in the gas phase and II in $n$-dodecane. The inclusion of dispersion corrections are more significant for the tetra-ethyl carbamide than for monoamides derivatives. Dispersion attrac- 
tive interactions stabilize geometry I over geometry II in the gas phase and in $n$-dodecane. This is attributed to the weak interactions that take place between the alkyl chains and nitrate ions. Such interactions are becoming more important as the number of alkyl groups increases and are also more important in the gas phase and in $n$-dodecane than in the more polar DMA solution which counterbalances their strengths. Finally, considering the small energy difference in solution it is not possible to discriminate between both structures which may coexist in solution. The structural parameters are reported in Table 10 for geometry II and in the ESI for geometry I. The hydrogen bond distances are slightly longer with the carbamides than with the monoamides (in the gas phase, the lengthening of $\mathrm{O}_{\text {nit }}-\mathrm{H}$ distance is $0.03 \AA$ from C4E to EEE and $0.05 \AA$ for the $\mathrm{O}_{\text {nit }}-\mathrm{O}_{\mathrm{L}}$ distance). In geometry $\mathrm{I}$, this is the reverse, the hydrogen bond distance is shorter with carbamide, O-H distance decreases by $0.08 \AA$ from C4E to EEE.

Table 9 Selected interatomic distances (average values in $\AA$ ) calculated in the $\left[\mathrm{Pu}\left(\mathrm{NO}_{3}\right)_{4} \mathrm{~L}_{2}\right]$ complexes with carbamides optimized in the gas phase.

\begin{tabular}{lccccc}
\hline Ligand & $d_{\mathrm{Pu}-\mathrm{O}_{\mathrm{L}}}$ & $d_{\mathrm{Pu}-\mathrm{O}_{\text {nit }}}$ & $d_{\mathrm{Pu}-\mathrm{N}_{\text {nit }}}$ & $d_{\mathrm{O}-\mathrm{C}}$ & $d_{\mathrm{C}-\mathrm{N}}$ \\
\hline $\mathrm{C} 4 \mathrm{M}$ & 2.346 & 2.490 & 2.936 & 1.256 & 1.354 \\
$\mathrm{C} 4 \mathrm{E}$ & 2.358 & 2.493 & 2.939 & 1.252 & 1.349 \\
solution & n-dodecane & & & & \\
$\mathrm{C} 4 \mathrm{M}$ & 2.326 & 2.497 & 2.941 & 1.260 & 1.346 \\
$\mathrm{C} 4 \mathrm{E}$ & 2.345 & 2.499 & 2.943 & 1.267 & 1.352 \\
solution & DM & & & & \\
C4M & 2.298 & 2.510 & 2.952 & 1.268 & 1.342 \\
$\mathrm{C} 4 \mathrm{E}$ & 2.323 & 2.508 & 2.951 & 1.273 & 1.348 \\
\hline
\end{tabular}

Table 10 Selected interatomic distances (average values $d$ in $\AA)^{a}$ and hydrogen bond angle $\left(\alpha_{O-H-O}\right)$ in degrees calculated for the $\left[\mathrm{Pu}\left(\mathrm{NO}_{3}\right)_{6}\right]\left(\mathrm{HL}_{2}\right)$ complex in geometry $\mathrm{II}$ in the gas phase and in solution. $^{a}$

\begin{tabular}{|c|c|c|c|c|c|c|c|}
\hline & $d_{\mathrm{Pu}-\mathrm{O}_{\text {nit1 }}}$ & $d_{\mathrm{Pu}-\mathrm{O}_{\mathrm{nit} 2}}$ & $d_{\mathrm{Pu}-\mathrm{N}_{\mathrm{L}}}$ & $d_{\mathrm{Pu}-\mathrm{N}_{\mathrm{L}}}$ & $d_{\mathrm{O}_{\mathrm{nit} 2}-\mathrm{O}_{\mathrm{L}}}$ & $d_{\mathrm{O}_{\text {nit }}-\mathrm{H}}$ & $\alpha_{\mathrm{OHO}}$ \\
\hline \multicolumn{8}{|c|}{ gas phase } \\
\hline C4M & 2.523 & 2.563 & 5.178 & 6.190 & 2.557 & 1.552 & 169 \\
\hline CAE & 2.516 & 2.580 & 5.608 & 7.016 & 2.573 & 1.561 & 174 \\
\hline \multicolumn{8}{|c|}{ solution $n$-dodecane } \\
\hline C4M & 2.524 & 2.560 & 5.234 & 6.296 & 2.600 & 1.606 & 169 \\
\hline C4E & 2.529 & 2.571 & 5.695 & 7.071 & 2.613 & 1.613 & 174 \\
\hline \multicolumn{8}{|c|}{ solution DMA } \\
\hline C4M & 2.525 & 2.561 & 5.513 & 6.667 & 2.693 & 1.712 & 169 \\
\hline C4E & 2.525 & 2.559 & 5.863 & 7.178 & 2.692 & 1.711 & 170 \\
\hline
\end{tabular}

${ }^{a} O_{\text {nit } 1}$ denotes oxygen from nitrate ions which are not involved in hydrogen bond. $O_{\text {nit } 2}$ denotes oxygen from nitrate ions which are involved in hydrogen bond.

Complexation energies are given in Table 12 For outer-sphere complexes, the lowest energy geometry was taken at each level of calculation. Energies were calculated in the gas phase and in solution. Results are compared with the PEE monoamide. For inner-sphere complexation, the relative complexation free energies are strongly dependent on dispersion corrections. Namely, at the PBE0 level, when the length of the carbamide alkyl
Table 11 Free energy differences between the two outer-sphere geometries I and II of the $\left[\mathrm{Pu}\left(\mathrm{NO}_{3}\right)_{6}\right]\left(\mathrm{HL}_{2}\right)$ carbamide complexes. The values are in $\mathrm{kJ} \mathrm{mol}^{-1}$ and were computed in the gas phase, in $n$-dodecane and in DMA solvents.

\begin{tabular}{lrc}
\hline & C4M & C4E \\
\hline Gas PBE0 & 4 & 7 \\
Dodecane PBE0 & -4 & -2 \\
DMA PBE0 & 1 & -3 \\
Gas PBE0-D3 & 6 & 17 \\
Dodecane PBE0-D3 & -3 & 7 \\
DMA PBE0-D3 & -1 & -3 \\
\hline
\end{tabular}

groups increases (from C4M to C4E) or from monoamide to carbamide (PEE to C4E), inner-sphere complexation is destabilized by $9 \mathrm{~kJ} \mathrm{~mol}^{-1}$ to $17 \mathrm{~kJ} \mathrm{~mol}^{-1}$, in the gas phase as well as in solution. In the presence of dispersion corrections, this is the reverse, inner sphere is stabilized, attractive dispersion forces overbalance steric hindrance effects. Dispersion interactions are likely to be overestimated from such calculations since the competitive dispersion interactions with alkyl chains from the solvent are not properly taken into account. However, these results emphasize the key role of weak interactions in these systems. For outer-sphere complexation, the lengthening of the alkyl group destabilizes the complexation in the gas phase. Solvent effects counterbalance steric hindrance effects in the outer sphere and favor C4E complexation compared to C4M. There is no strong influence of dispersion corrections. The replacement of PEE by C4E slightly favors outersphere complexation in the gas phase and in $n$-dodecane.

Table 12 Complexation free energies when going from C4M to C4E and from PEE to C4E ligands for reactions (3) and (4). The values in $\mathrm{kJ} \mathrm{mol}^{-1}$ and were calculated in the gas phase and in solution at the PBE0 and PBE0-D3 levels of theory.

\begin{tabular}{lrc|rc}
\hline & \multicolumn{2}{c|}{ inner-sphere } & \multicolumn{2}{c}{ outer sphere } \\
& C4M $\rightarrow$ C4E & PEE $\rightarrow$ C4E & C4M $\rightarrow$ C4E & PEE $\rightarrow$ C4E \\
\hline Gas PBE0 & 9 & 17 & 11 & 5 \\
Dod. PBE0 & 11 & 10 & 4 & 6 \\
DMA PBE0 & 13 & 9 & -2 & -8 \\
Gas PBE0-D3 & -13 & -3 & 17 & -1 \\
Dod. PBE0-D3 & -11 & -9 & 6 & -3 \\
DMA PBE0-D3 & -9 & -9 & -6 & -10 \\
\hline
\end{tabular}

\section{Conclusion}

From this work it is possible to get a better understanding of the strong influence of amide structure on plutonium extraction. Experimentally, a simple modification of the alkyl chain attached to the carbonyl group can suppress plutonium extraction at low and high acidity even though amide operates through different coordination modes. Complexation energies were calculated for inner and outer-sphere complexations, which take place in weakly acidic and strong acidic conditions, respectively. For both inner and outer-sphere complexes, it is found that the introduction of a bulky alkyl group on the carbonyl side diminishes strongly the complexation energy. This is fully consistent with the measured 
monamide extraction properties. The influence of the bulkiness of the alkyl group is as or even more important for outer than for inner-sphere interactions. This was unexpected when considering that there is less flexibility and stronger steric constraints in the inner sphere. This is attributed to specific electrostatic interactions between the two outer-sphere amide ligands and two nitrate ions of $\mathrm{Pu}\left(\mathrm{NO}_{3}\right)_{6}{ }^{2-}$. By increasing the polarity of the solution, the outer-sphere protonated ligands remain attached to $\mathrm{Pu}\left(\mathrm{NO}_{3}\right)_{6}{ }^{2-}$ but alkyl groups move away and their interactions with nitrate ions diminish. As a consequence, solvent effects are very significant for outer-sphere complexation while there are small for inner-sphere complexation. It gives the key possibility to tune the substituent effect by changing the polarity of the solution. When changing the ligand, from monoamide to carbamide, the results show that weak interactions such as dispersion forces may have a remarkable impact on ligand binding affinities and on plutonium(IV) extraction. In order to predict ligand affinity of different families, it will be essential to go beyond the static DFT quantum chemical calculations with implicit treatments of solvent effects and to perform explicit solvent simulations.

\section{Conflicts of interest}

There are no conflicts to declare.

\section{Acknowledgements}

We acknowledge support by the French government through the Program "Investissement d'avenir" (Grants LABEX CaPPA/ANR11-LABX-0005-01 and I-SITE ULNE/ANR16-IDEX-0004 ULNE), as well as by the Ministry of Higher Education and Research, Hauts de France council and European Regional Development Fund (ERDF) through the Contrat de Projets État Region (CPER CLIMIBIO). Furthermore, this work was granted access to the HPC resources of CINES/IDRIS/TGCC under the allocation 20192020 (A0070801859) made by GENCI. We also acknowledge the CEA for the Ph.D. grant given to A.F.

\section{Notes and references}

1 C. Pohllandt and J. S. Fritz, J. Chromatogr. A, 1979, 176, 189197.

2 H. Narita, M. Tanaka, K. Morisaku and T. Abe, Hydrometallurgy, 2006, 81, 153 - 158.

3 E. D. Doidge, L. M. M. Kinsman, Y. Ji, I. Carson, A. J. Duffy, I. A. Kordas, E. Shao, P. A. Tasker, B. T. Ngwenya, C. A. Morrison and J. B. Love, ACS Sustain. Chem. Eng., 2019, 7, 1501915029.

4 B. Mahanty, A. S. Kanekar, S. A. Ansari, A. Bhattacharyya and P. K. Mohapatra, Radiochimica Acta, 2019, 107, 369-376.

5 C. Pohlandt and J. S. Fritz, Talanta, 1979, 26, 395-399.

6 T. Siddall III, J. Phys. Chem., 1960, 14, 1863-1866.

7 T. Siddall III, Application of amides as extractants, u Pont de Nemours (E. I.); Co. Savannah River Lab., Aiken, S.C. Technical Report DP-541, 1961.

8 N. Condamines and C. Musikas, Solvent Extr. Ion Exc., 1992, 10, 69-100.

9 K. McCann, J. A. Drader and J. C. Braley, Sep. Purif. Rev., 2018,
47, 49-65.

10 G. Milanole, E. Russello, C. Marie, M. Miguirditchian and C. Sorel, Dissymmetric N, N-dialkylamides used particularly for separating uranium (VI) from plutonium (IV), synthesis thereof and uses of same, WO/2018/138441, 2018.

11 C. Berger, C. Marie, D. Guillaumont, E. Zekri and L. Berthon, Solvent. Extr. Ion Exc., 2019, 37, 111-125.

12 D. Prabhu, G. Mahajan and G. Nair, J. Radioanal. Nucl. Chem., 1997, 224, 113-117.

13 K. Gupta, V. Manchanda, M. Subramanian and R. Singh, SEPARATION SCIENCE AND TECHNOLOGY, 2000, 35, 16031617.

14 K. Gupta, V. Manchanda, M. Subramanian and R. Singh, SOLVENT EXTRACTION AND ION EXCHANGE, 2000, 18, 273-292.

15 V. Manchanda and P. Pathak, Sep. Purif. Technol., 2004, 35, 85-103.

16 K. Gupta, V. Manchanda, M. Subramanian and R. Singh, Solvent Extraction and Ion Exchange, 2000, 18, 273-292.

17 K. McCann, J. A. Drader and J. C. Braley, Sep. Purif. Rev., 2018, 47, 49-65.

18 Y. Ban, S. Hotoku, N. Tsutsui, A. Suzuki, Y. Tsubata and T. Matsumura, Procedia Chemistry, 2016, 21, 156 - 161.

19 E. Acher, Y. Hacene Cherkaski, T. Dumas, C. Tamain, D. Guillaumont, N. Boubals, G. Javierre, C. Hennig, P. L. Solari and M.-C. Charbonnel, Inorg. Chem., 2016, 55, 5558-5569.

20 Y. Ban, S. Hotoku, N. Tsutsui, A. Suzuki, Y. Tsubata and T. Matsumura, Procedia Chem., 2016, 21, 156 - 161.

21 B. Mahanty, A. Bhattacharyya, A. S. Kanekar and P. Mohapatra, Solvent Extr. Ion Exc., 2020, 38, 290-303.

22 F. Rodrigues, G. Ferru, L. Berthon, N. Boubals, P. Guilbaud, C. Sorel, O. Diat, P. Bauduin, J. P. Simonin, J. P. Morel, N. Morel-Desrosiers and M. C. Charbonnel, Mol. Phys., 2014, 112, 1362-1374.

23 P. G. Allen, D. K. Veirs, S. D. Conradson, C. A. Smith and S. F. Marsh, Inorg. Chem., 1996, 35, 2841-2845.

24 E. Acher, T. Dumas, C. Tamain, N. Boubals, P. L. Solari and D. Guillaumont, Dalton Trans., 2017, 46, 3812-3815.

25 K. McCann, S. I. Sinkov, G. J. Lumetta and J. C. Shafer, New J. Chem., 2018, 42, 5415-5424.

26 S. Pahan, A. Boda and S. M. Ali, Theor. Chem. Acc., 2015, 134, 41.

27 S. O. Odoh and G. Schreckenbach, J. Phys. Chem. A, 2011, 115, 14110-14119.

28 M. Šulka, L. Cantrel and V. Vallet, J. Phys. Chem. A, 2014, 118, 10073-10080.

29 M. J. Frisch, G. W. Trucks, H. B. Schlegel, G. E. Scuseria, M. A. Robb, J. R. Cheeseman, G. Scalmani, V. Barone, G. A. Petersson, H. Nakatsuji, X. Li, M. Caricato, A. V. Marenich, J. Bloino, B. G. Janesko, R. Gomperts, B. Mennucci, H. P. Hratchian, J. V. Ortiz, A. F. Izmaylov, J. L. Sonnenberg, D. WilliamsYoung, F. Ding, F. Lipparini, F. Egidi, J. Goings, B. Peng, A. Petrone, T. Henderson, D. Ranasinghe, V. G. Zakrzewski, J. Gao, N. Rega, G. Zheng, W. Liang, M. Hada, M. Ehara, K. Toyota, R. Fukuda, J. Hasegawa, M. Ishida, T. Nakajima, 
Y. Honda, O. Kitao, H. Nakai, T. Vreven, K. Throssell, J. A. Montgomery, Jr., J. E. Peralta, F. Ogliaro, M. J. Bearpark, J. J. Heyd, E. N. Brothers, K. N. Kudin, V. N. Staroverov, T. A. Keith, R. Kobayashi, J. Normand, K. Raghavachari, A. P. Rendell, J. C. Burant, S. S. Iyengar, J. Tomasi, M. Cossi, J. M. Millam, M. Klene, C. Adamo, R. Cammi, J. W. Ochterski, R. L. Martin, K. Morokuma, O. Farkas, J. B. Foresman and D. J. Fox, Gaussian 16 Revision C.01, 2016, Gaussian Inc. Wallingford CT.

30 C. Adamo and V. Barone, J. Chem. Phys., 1999, 110, 61586170.

31 P. G. Allen, D. K. Veirs, S. D. Conradson, C. A. Smith and S. F. Marsh, Inorg. Chem., 1996, 35, 2841-2845.

32 F. Weigend, Phys. Chem. Chem. Phys., 2006, 8, 1057-1065.

33 A. Moritz, X. Cao and M. Dolg, Theor. Chem. Acc., 2007, 118, $845-854$.

34 A. Moritz, X. Cao and M. Dolg, Theor. Chem. Acc., 2007, 118, 845-854.

35 X. Cao, M. Dolg and H. Stoll, JOURNAL OF CHEMICAL PHYSICS, 2003, 118, 487-496.

36 S. Grimme, J. Antony, S. Ehrlich and H. Krieg, J. Chem. Phys.,
2010, 132, 154104.

37 F. Furche, R. Ahlrichs, C. Hättig, W. Klopper, M. Sierka and F. Weigend, Wiley Interdisciplinary Reviews: Computational Molecular Science, 2014, 4, 91-100.

38 R. A. Kendall, T. H. Dunning and R. J. Harrison, J. Chem. Phys., 1992, 96, 6796-6806.

39 M. Sierka, A. Hogekamp and R. Ahlrichs, J. Chem. Phys., 2003, 118, 9136-9148.

40 J. Tomasi, B. Mennucci and R. Cammi, Chemical reviews, 2005, 105, 2999-3094.

41 R. G. Surbella, L. C. Ducati, J. Autschbach, K. L. Pellegrini, B. K. McNamara, J. M. Schwantes and C. L. Cahill, Chem. Commun., 2018, 54, 12014-12017.

42 M. B. Doran, A. J. Norquist and D. O'Hare, Inorg. Chem., 2003, 42, 6989-6995.

43 T. Sukhbaatar, M. Duvail, T. Dumas, S. Dourdain, G. Arrachart, P. L. Solari, P. Guilbaud and S. Pellet-Rostaing, Chem. Commun., 2019, 55, 7583-7586.

44 C. E. Ruggiero, J. H. Matonic, S. D. Reilly and M. P. Neu, Inorg. Chem., 2002, 41, 3593-3595. 